\title{
Bauran Pemasaran Dan Pengaruh Perilaku Konsumen Dalam Membeli Produk AICE Di UD. Stan Jaya Kelurahan Paupire Kecamatan Ende Tengah Kabupaten Ende
}

\author{
Yenny Kila, Yosef Moan Banda \\ e-mail: yosefmoan@gmail.com
}

Program Studi Pendidikan Ekonomi, FKIP, Universitas Flores

\begin{abstract}
ABSTRAK: Penelitian ini bertujuan untuk mengetahui: bauran pemasaran dan pengaruh Perilaku Konsumen Dalam Membeli Produk Aice Di UD. Stan Jaya. Pendekatan penelitian adalah Deskriptif kuantitatif. Pengumpulan data dilakukan dengan menggunakan teknik observasi, kuisioner dan dokumentasi. Teknis analisis data yang digunakan Uji kolmogrovsmirnov, uji dilakukan dengan bantuan program spss 16.0 for windows dan uji hipotesis menggunakan uji t. Sedangkan sampel dalam penelitian ini adalah konsumen es krim Aice sebanayak 50 orang. Temuan penelitian menunjukan bahwa secara simultan bauran pemasaran berpengaruh terhadap perilaku konsumen. Secara parsial, produk, harga, promosi dan lokasi berpengaruh terhadap perilaku konsumen. Dimana rhitung $\geq \mathrm{r}$ tableyaitu 1,758 $\geq$ 0,284 hal ini berarti ada berpengaruh signifikaan antara bauran pemasaran dengan perilaku konsumen dalam membeli produk Aice. Lokasi adalah yang paling dominan mempengaruhi perilaku konsumen.
\end{abstract}

Kata kunci: bauran pemasaran, perilaku konsumen.

ABSTRACT: This study aims to determine: the marketing mix and the influence of consumer behavior in buying Aice products at UD. Stan Jaya. The research approach is quantitative descriptive. Data collection was carried out using observation, questionnaire and documentation techniques. Technical analysis of the data used kolmogrov-smirnov test, the test was carried out with the help of the SPSS 16.0 program for windows and hypothesis testing using the t test. While the samples in this study were Aice ice cream consumer of 50 people. The research findings show that marketing mix simultaneously influences consumer behavior. Partialy, product, price, promotion and location influence consumer behavior. Where the count $\geq r$ table is $1.758 \geq 0.284$ this means that there is a significant effect between the marketing mix with consumer behavior in buying Aice products. Location is the most dominant influence on consumer behavior.

Keywords: consumer behavior, marketing mix.

\section{PENDAHULUAN}

Pemasaran merupakan aktivitasaktivitas sekitar kehidupan manusia, sejak bangun pagi hingga tidur malam. Aktivitas -aktivitas dimaksud karena pada dasarnya manusia mempunyai kebutuhan baik lahir maupun batin yang harus dipenuhi. Pengertian pemasaran secara bisnis yakni mengindentifikasi kebutuhan dan keinginan konsumen, menetapkan pasar sasaran mana yang dapat dilayani secara baik oleh perusahaan, merancang produk dan program yang tepat dalam "melayani konsumen". Sesuai pandangan dan pola hidup masyarakat.

Kotler (1999 : 201) mendefenisikan Pemasaran adalah suatu proses soasial dan manejerial yang di dalamnya terdapat 
individu dan kelompok yang mendapatkan apa yang mereka butuhkan dan inginkan dengan menciptakan, menawarkan, dan mempertukarkan produk yang bernilai dengan pihak lain.

Manakala dikaji secara spesifik maka prinsip-prinsip strategi pemasaran tidak terlepas satu sama lain. Konsekuensi dari penerapan bauran pemasaran adalah meningkatkan jumlah kuantitas, jumlah pelayanan, dan jumlah pelanggan dari penerapan strategi pemasaran. Rambat Lupiyoadi, (2013: 92), mengatakan bahwa bauran pemasaran merupakan perangkat/alat bagi pemasar yang terdiri atas berbagai unsur suatu program pemasaran yang perlu dipertimbangkan agar implementasi strategi pemasaran dan penentuan posisi yang ditetapkan dapat berjalan sukses.

Perilaku konsumen pada dasarnya adalah suatu proses yang kompleks yang mencakup beberapa aktivitas, peran, dan keterlibatan manusia pada berbagai keadaan dari pengaruh faktor lingkungan. Pemahaman akan perilaku konsumen dapat diaplikasikan dalam beberapa hal, salah satunya adalah untuk merancang sebuah strategi pemasaran yang baik.

Prasetijo, (2005: 4), mengatakan bahwa mempelajari perilaku konsumen sangatlah penting, guna mengetahui kebutuhan, keinginan, dan selera konsumen serta pengambilan keputusan dalam pembelian.

Keputusan Pembelian Konsumen merupakan sebuah tindakan yang dilakukan konsumen untuk membeli atau tidak suatu produk. Untuk itu Setiap produsen berusaha dengan berbagai strategi untuk meyakinkan konsumen dalam memutuskan untuk membeli produknya (Malau.2017:217).

Perilaku yang ditunjukan seorang konsumen dalam pembelian disebabkan oleh beberapa faktor, (1) setiap orang memiliki sikap dan prefensi yang berbeda, (2) ciri kepribadian, (3) usia, (4) pendapatan dan (5) gaya /pola hidup
Orientasi pemasaran saat ini telah mengalami perubahan yang cukup besar, dimana orientasi tidak pada produk, melainkan beralih keorientasi pada konsumen, hal ini menyebabkan perusahaan diharuskan tidak hanya mampu memenuhi kebutuhan konsumen saja, tetapi juga harus dapat memuaskan konsumen.

Berdasarkan hasil pelacakan di lapangan menunjukan adanya persaingan antar pemasar untuk merebut konsumen, kurangnya informasi tentang penjualan es krim oleh perusahaan, perusahaan tidak sebatas memenuhi kebutuhan konsumen tetapi harus dapat memuaskan konsumen, tuntuan pihak konsumen akan pelayanan yang prima dari pihak produsen, kurangnya fasilitas dan sarana pendukung dalam pemasaran es krim

Kegiatan pemasaran yang baik dan tepat diperlukan informasi guna mengantisipasi perubahan mengenai selera konsumen atas produk yang ditawarkan., juga harus mampu merebut hati konsumen melalui pendekatkan pelayanan yakni distribusi es krim sampai ke gang-gang perumahan Penduduk.

\section{LANDASAN TEORI \\ Pemasaran}

Stanton (dalam Tambajong 2013 : 1293),mendefenisikan pemasaran adalah suatu system dari kegiatan bisnis yang dirancang untuk merencanakan, menentukan harga, mempromosikan dan mendistribusikan produk yang dapat memuaskan keinginan dalam mencapai tujuan perusahaan.

Selanjutnya Kotler, et al (2012 : 29), "marketing as the process by which companies create value for customers and build strong costumer relationship in order to capture value from costumers in return", artinya menyatakan bahwa pemasaran sebagai proses dimana perusahaan menciptakan nilai bagi pelanggan dan membangun hubungan pelanggan yang kuat untuk menangkap nilai dari pelanggan sebagai imbalan. 
Sedangkan Abdullah ,et al (2012: 14), pemasaran adalah suatu proses sosial dan manajerial di mana individu dan kelompok mendapatkan kebutuhan dan keinginan mereka dengan menciptakan, menawarkan dan bertukar sesuatu yang bernilai satu sama lain.

\section{Bauran Pemasaran}

Swastha et al, (2005 : 10) mendefinisikan konsep pemasaran adalah sebuah falsafah bisnis yang menyatakan bahwa pemuasan kebutuhan konsumen merupakan syarat ekonomi dan sosial bagi kelangsungan hidup perusahaan. Bagian pemasaran pada suatu perusahaan memegang peranan yang sangat penting dalam rangka mencapai besarnya volume penjualan, karena dengan tercapainya sejumlah volume penjualan yang diinginkan berarti kinerja bagian pemasaran dalam memperkenalkan produk telah berjalan dengan benar. Penjualan dan pemasaran sering dianggap sama tetapi sebenarnya berbeda.

Tujuan utama konsep pemasaran adalah melayani konsumen dengan mendapatkan sejumlah laba, atau dapat diartikan sebagai perbandingan antara penghasilan dengan biaya yang layak. Ini berbeda dengan konsep penjualan yang menitikberatkan pada keinginan perusahaan.

Rambat Lupiyoadi, (2013: 92), mengatakan bahwa bauran pemasaran merupakan perangkat/alat bagi pemasar yang terdiri atas berbagai unsur suatu program pemasaran yang perlu dipertimbangkan agar implementasi strategi pemasaran dan penentuan posisi yang ditetapkan berjalan sukses.

Lebih Lanjut William (1999: 12), mengemukakan bahwa bauran pemasaran yaitu menginformasikan bahwa untuk meningkatkan nilai saing yang tinggi dari suatu perusahaan, maka penguasaan terhadap strategi pemasaran menjadi target utama. Bauran pemasaran tersebut terdiri dari produk (product), harga (price), distribusi (distribution) dan promosi (promotion).
Menurut Kotler (2002: 18), bauran pemasaran (marketing mix) adalah seperangkat alat pemasaran yang digunakan perusahaan untuk terusmenerus mencapai tujuan pemasarannya di pasar sasarannya. Para pemasar pada umumnya menggunakan bauran pemasaran ini sebagai alat untuk mendapatkan tanggapan yang diinginkan oleh perusahaan dari pasaran mereka atas produk yang ditawarkan oleh perusahaan atau untuk menciptakan pembelian atas produk perusahaan.

Kotler (2006 : 62) mengemukakan bahwa: "Bauran Pemasaran (Marketing Mix) adalah kumpulan alat-alat pemasaran taktis terkendali yang di padukan perusahaan untuk menghasilkan respons yang diinginkannya di pasar sasaran". Bauran pemasaran terdiri dari semua hal yang dapat dilakukan perusahaan untuk mempengaruhi permintaan produknya. Berbagai kemungkinan ini dapat dikelompokkan menjadi empat kelompok variabel yang disebut "empat P": Product (Produk), Price (Harga), Place (Tempat) dan Promotion (Promosi).

Pride (2010 : 5 ) mengemukakan bahwa"Marketing mix four marketing activities- product, distribution, promotion, and pricing-that a firm can control to meet the needs of customers within its target markets".

Faktor-faktor Bauran Pemasaran yang Mempengaruhi Keputusan Pembelian Konsumen adalah sebagai berikut: 1 . Produk (Product); 2. Harga (Price); 3. Promosi (Promotion); 4. Lokasi (Place).

\section{Perilaku Konsumen}

Undang-Undang No. 8 Tahun 1999 pasal 1 ayat 2 tentang perlindungan konsumen, pengertian konsumen adalah setiap orang pemakai barang / jasa yang tersedia di masyarakat, baik bagi kebutuhan diri sendiri, keluarga, orang lain, atau makhluk hidup lain dan tidak

Kotler et al (2008:214): mengatakan perilaku konsumen adalah studi, bagaimana individu, kelompok dan 
organisasi memilih, membeli, menggunakan dan menempatkan barang, jasa, ide atau pengalaman untuk memuaskan keinginan dan kebutuhan mereka.

Selanjutnya schiffman et al (2008:6): mendefenisikan perilaku konsumen menggambarkan cara individu mengambil keputusan untuk memanfaatkan sumberdaya mereka yang tersedia (waktu, uang, usaha) guna membeli barang-barang yang berhubungan dengan konsumsi.

\section{METODE PENELITIAN}

Penelitian ini adalah penelitian kuantitatif. sebagai metode yang berlandaskan pada filsafat positivisme, yang digunakan untuk meneliti populasi dan sampel tertentu, pengumpulan data menggunakan instrument penelitian, analisa data adalah statistik, dengan tujuan untuk menguji hipotesis yang ada.

Penelitian ini dilakukan di Kelurahan Paupire Kecamatan Ende Tengah Kabupaten Ende. Selama 2 bulan yakni bulan Mei dan Juni 2019. Populasi dalam penelitian adalah seluruh konsumen UD. Stan Jaya yang membeli es krim Aice. Untuk menentukan sampel, peneliti menggunakan teknik pusposive random sampling, yakni teknik pengambilan sampel berdasarkan pertimbangan. Sampel dipilih sebanyak 50 konsumen.

Pengumpulan data dengan teknik observasi dimana peneliti terjun langsung ke lapangan untuk mengamati dan mengumpulkan data. Sedangkan teknik angket merupakan teknik pengumpulan data yang dilakukan dengan cara memberi seperangkat pertanyaan atau pernyataan tertulis kepada responden untuk dijawabnya. Sementara teknik dokumentasi digunakan sebagai sarana pembantu peneliti dalam mengumpulkan data atau informasi

Analisis dan pengolahan data, peneliti mengerjakan melalui tahapantahapan sebagai berikut:

1. Analisis Regresi Linear Berganda
Uji analisis regresi Berganda merupakan uji digunakan untuk mencari bentuk pengaruh secara parsial (sendiri-sendiri) dan simultan (bersama-sama) antara variabel bebas/independen $(\mathrm{X})$ dan variabel terikat/dependen $(Y)$. Dengan rumus sebagai berikut: $Y=a+b 1 \times 1+b 2 \times 2+b 3 \times 3$ $+b 4 \times 4+e$

Dimana :

$\mathrm{Y}=$ keputusan pembelian konsumen

$\mathrm{a}=$ konstanta dari keputusan regresi

b1 = koefisien regresi dari variabel $\mathrm{X} 1$ (produk/ product)

b2 = koefisien regresi dari variabel X2 (harga/ price)

b3 = koefisien regresi dari variabel X3 (lokasi/ place)

b4 $=$ koefisian regresi dari variabel $\mathrm{X} 4$ (promosi/ promotion)

$\mathrm{X} 1=\operatorname{produk}($ product $)$

$\mathrm{X} 2=$ harga (price)

$\mathrm{X} 3$ = lokasi

$\mathrm{X} 4$ = promosi

$\mathrm{e}=$ variabel pengganggu

2. Uji Hipotesis

a. Uji F

Uji ini digunakan untuk mengetahui adanya tingkat pengaruh variabel bebas/dependen secara simultan (bersama-sama) terhadap variabel terikat/independen. Dengan rumusan sebagai

berikut:

beanen

$=\frac{\left.\mathrm{R}^{2} / \mathrm{k}\right)}{\left(1-\mathrm{R}^{2}\right)(\mathrm{n}-\mathrm{k}-1)}$

b. Uji t

Uji $t$ ini digunakan untuk menguji secara parsial yang betujuan untuk mengetahui pengaruh dari tiap-tiap variabel bebas/dependen terhadap variabel terikat/independen. sebagai berikut: 


$$
\mathrm{t}=\frac{b}{s b}
$$

Keterangan:

$\mathrm{b}=$ Koefesien Regresi.

$\mathrm{sb}=$ Estimasi Kesalahan Standart b

Dasar pengambilan keputusan sebagai berikut:

a. Dengan membandingkan nilai $\mathrm{t}$ hitungnya dengan $t$ tabel. Apabila $\mathrm{t}$ tabel $>\mathrm{t}$ hitung, maka H0 diterima dan H1 ditolak. Apabila $t$ tabel $<\mathrm{t}$ hitung, maka $\mathrm{H} 0$ ditolak dan $\mathrm{H} 1$ diterima Dengan tingkat signifikansi 5\%.

b. Dengan menggunakan angka probabilitas signifikansi. Apabila angka probabilitas signifikansi > 0,05, maka $\mathrm{H} 0$ diterima dan $\mathrm{H} 1$ ditolak. Apabila angka probabilitas signifikansi < 0,05, maka H0 ditolak dan H1 diterima.

\section{PEMBAHASAN}

Dalam analisis hubungan bauran pemasaran dan perilaku konsumen peneliti menggunakan rumus korelasi product moment. Untuk mengetahui ratarata dari variabel $\mathrm{x}$ dan $\mathrm{y}$ digunakan rumus:

$$
\begin{aligned}
x & =\frac{\sum x}{n} & x & =\frac{\sum y}{n} \\
& =\frac{410}{50} & & =\frac{180}{50} \\
& =8,2 & & =3,6
\end{aligned}
$$

Dari data tersebut kemudian dimasukan kerumus perhitungan product moment sebagai berikut :

$$
r x y=\frac{N \cdot \sum X Y\left(\sum X\right)\left(\sum Y\right)}{\sqrt{\left\{N \cdot \sum X^{2}-\left(\sum X\right)^{2}\right\}\left\{N \cdot \sum Y^{2}-\left(\sum Y\right)^{2}\right\}}}
$$

Perhitungan di atas dapat diketahui bahwa $r_{x y}$ sebesar 1.75810 hasil tersebut juga didukung dengan hasil perhitungan

\begin{tabular}{|c|c|c|c|}
\hline \multicolumn{4}{|c|}{ Correlations } \\
\hline & & BAURAN & \\
\hline & & PEMASAR & PERILAKU \\
\hline & & AN & KONSUMEN \\
\hline BAURAN & Pearson & \multirow[t]{2}{*}{1} & \multirow[t]{2}{*}{,013 } \\
\hline \multirow[t]{3}{*}{ PEMASARAN } & Correlation & & \\
\hline & Sig. (2-tailed) & & ,928 \\
\hline & $\mathrm{N}$ & 50 & 50 \\
\hline PERILAKU & Pearson & \multirow[t]{2}{*}{, 013} & \multirow[t]{2}{*}{1} \\
\hline \multirow[t]{3}{*}{ KONSUMEN } & Correlation & & \\
\hline & Sig. (2-tailed) & ,928 & \\
\hline & $\mathrm{N}$ & 50 & 50 \\
\hline
\end{tabular}
melalui SPSS IBM 25 sebagaimana terlinat pada tabel berikut ini:

Tabel

\section{Hasil Out Put IBM 25}

Kemudian data diatas diinterprestasikan sebagi berikut: Secara sederhana perhitungan antara variabel $\mathrm{x}$ dan y memiliki tanda positif(+) yang berarti terdapat korelasi yang berbanding terbalik. interprestasi dengan berpedoman pada tabel " $r$ " product moment yaitu $: \mathrm{df}=$ $\mathrm{N}-\mathrm{nr}$ df $=50-2=48$. Tabel nilai " $r$ " product moment dengan df sebesar 48 pada taraf signifikan $5 \%$ diperoleh bahwa " $\mathrm{r}$ " tabel $=0,284$.

Hal ini menunjukan bahwa korelasi antara bauran pemasaran dan perilaku konsumen dalam membeli produk aice berbanding terbalik, yang mengandung makna bahwa bauran 
pemasaran yang tinggi akan diikuti oleh prilaku konsumen yang rendah.

\section{KESIMPULAN}

1. Ber dasarkan hasil penelitian membuktikan bahwa bagian dari variabel independen Bauran Pemasaran, yaitu Produk, Harga, Promosi dan lokasi mempunyai pengaruh yang positif dan signifikan terhadap variabel dependen yaitu perilaku konsumen yang berlokasi di jalan Samratulangi Kelurahan Paupire Kecamatan Ende Tengah Kabupaten Ende dalam membeli produk Aice dimana rhitung $\geq$ rtable Yaitu $1.758 \geq 0,284$.

2. Berdasarkan hasil uji t menunjukan hasil penelitian bahwa bagian dari variabel independen Bauran Pemasaran yang lebih dominan berpengaruh adalah lokasi yang menunjukan hasil tertinggi yaitu 92,0\%. Hasil tersebut dapat disimpulkan bahwa Lokasi berpengaruh terhadap perilaku konsumen dalam membeli produk Aice.

\section{Daftar Pustaka}

Assauri, Sofjan, (2011.)Manajemen Pemasaran. Cetakan ke-11. Penerbit PT RajaGrafindo Persada. Jakarta.

Basu Swastha dan Hani Handoko, Manajemen Perusahaan Analisa Perilaku Konsumen, Yogyakarta : Liberty Edisi Pertama.

Bilson, Simamora(2002). Panduan Riset Perilaku Konsumen. PT Gramedia Pustaka Utama, Jakarta.

Khasanah Ukhwatul, Anantanyu, \& Sutarto (2009.) Pengaruh Pelaksanaan Bauran Pemasaran Terhadap Keputusan Konsumen Dalam Pembelian Jamu Tolak Angin di Surakarta. Artikel
Program studi Agribisnis Fakultas Pertanian Universitas Sebelas Maret.

Kotler Philip \& Keller K. Lane, (2009). Manajemen Pemasaran. Cetakan Keempat. Penerbit Macanan Jaya Cemerlang.

\section{Machfoedz,( 2005). Pengantar Pemasaran Modern. Cetakan Pertama. Penerbit Unit Penerbit \& Percetakan Akademi Manajemen Perusahaan YKPN, Yogyakarta.}

Priyatno, Duwi(, 2011). Buku Saku SPSS. Cetakan Pertama. Penerbit MediaKom. Yogyakarta.

Santosa P. Budi \& Ashari, (2005). Analisis Statistik dengan Microsoft Exccel $\&$ SPSS. Penerbit ANDI. Yogyakarta.

Sugiyono, (2010. ) Metode Penelitian Bisnis. Cetakan Ke-15. Penerbit Alfabeta. Bandung.

Tan, Erwin Rediono, (2011). Faktor Harga, Promosi, \& Pelayanan Terhadap Keputusan Konsumen Untuk Belanja di Alfamart Surabaya. ISSN 1978-4724 jurnal Kewirausahawan vol. 5 (2), Desember 2011.

Tjiptono, Fandy, (2008). Strategi Pemasaran. Edisi Ketiga. Penerbit ANDI. Yogyakarta.

Zikmun, Babin,( 2011). Riset Pemasaran. Edisi Sepuluh. Penerbit Salemba Empat. Jakarta.

Malau, Herman, (2017).manajemen pemasaran: teori dan aplikasi pemasaran era tradisional sampai era modernisasi global. Penerbit alfabet. Bandung. 